\title{
Article@Virology
}

\section{Characterization of Heliothis Virescens Ascovirus 3h orf21 that Encodes a Virion Protein}

\author{
Ying Zhao ${ }^{1,2}$, Huan $\mathrm{Yu}^{1,2}$, Ni Li ${ }^{1,2}$, GuoHua Huang ${ }^{1,2 *}$ \\ 1. Hunan Provincial Key Laboratory for Biology and Control of Plant Diseases and Insect Pests, \\ Changsha 410128, China \\ 2. College of Plant Protection, Hunan Agricultural University, Changsha 410128, China
}

\begin{abstract}
Homologues of Heliothis virescens ascovirus $3 \mathrm{~h}(\mathrm{HvAV}-3 \mathrm{~h})$ orf2 1 are found in 9 completely sequenced members of the ascoviruses, but so far their functions are unknown. Here, orf21 (3h-21) was cloned in-frame into a pET-28a bacterial expression vector. The fusion protein produced by this construct was used for the preparation of a polyclonal antiserum. RT-PCR analysis showed a single transcript of $3 h-21$ of approximately $0.7 \mathrm{~kb}$ was transcribed beginning at $24 \mathrm{~h}$ post-infection in infected Helicoverpa armigera larvae. Western blot analysis of extracts from HvAv-3h-infected Helicoverpa armigera larvae detected a $25.6 \mathrm{kDa}$ protein late in infection. This antiserum also reacted with a $25.6 \mathrm{kDa}$ protein in purified virions of HvAv-3h. The protein was not extensively modified post-translation. Immunoelectron microscopy confirmed that the $3 \mathrm{H}-21$ is associated with the structure of HvAV-3h virions.
\end{abstract}

Copyright@2012-2020 Published by Hong Kong Institute of Biologicals Standardization Limited. All rights reserved.

Article history: Submitted: 13/12/2019; Revised: 27/12/2019; Accepted: 30/12/2019

DOI:10.21092/jav.v8i4.114

Key Words: Ascovirus, HvAV-3h, Structural Protein, 3H-21

Abbreviations: dsDNA, double-stranded circular DNA; ORFs, Open Reading Frames; MCP, Major Capsid Protein; HvAV-3h, Heliothis virescens ascovirus $3 h$ SDS-PAGE,SDS-Polyacrylamide Gel Electrophoresis; TEM, Transmission Electron Microscopy .

\footnotetext{
* Corresponding author, PhD. , Major in Pathogeny biology ghhuang@hunau.edu.cn
} 


\section{Introduction}

The Ascoviridae are a family of large, enveloped virions containing doublestranded circular DNA (dsDNA) genomes of 110 to $200 \mathrm{kbp}^{[1,2]}$. Ascoviruses are infectious to the lepidopteran insects transmitted by parasitoid wasps, causing chronic infections with symptoms of stunted growth and milk-coloured haemolymph ${ }^{[3]}$. Some of them are a natural control agent of Helicoverpa armigera (Hübner), Spodoptera exigua (Hübner) and Spodoptera litura (Fabricius) such insect pests in agriculture and forestry ${ }^{[4]}$.

The Ascoviridae family has been divided into two genera: Ascovirus, which infects various members of the family Noctuidae (Insecta: Lepidoptera), and Toursvirus, which replicates in both its lepidopteran and parasitoid vector hosts ${ }^{[5]}$. Eleven isolates of ascoviruses have been completely sequenced to date ${ }^{[1,2,6-14]}$. Further researches reported that 25 ascovirus open reading frames (ORFs) were found to be conserved in all ascoviruses except the members of Toursvirus ${ }^{[2]}$. So far, researches of major capsid protein (MCP, TnAV-2a) and DNA-binding protein (P64, SfAV-1a) and ORF 117 (3H-117, HvAV-3h) has been carried out, but almost the viral genes remain to be explored ${ }^{[14-16]}$.

Heliothis virescens ascovirus $3 \mathrm{~h}$ (HvAV-3h) belongs to the Ascovirus genus. It cause high mortality among economically important insect pests, thereby controlling insect populations. We sequenced the
HvAV-3h genome which is $190,519 \mathrm{bp}$ in length with $185 \mathrm{ORFs}^{[3]}$. HvAV-3h orf 21 $(3 h-21)$ is located between nts 27,539 and 28,225 in the HvAV-3h genome, encodes a putative 228 aa with predicted molecular weight of $25.6 \mathrm{kDa}$.

Homologs of $3 \mathrm{H}-21$ have been identified in 9 completely sequenced ascoviruses suggesting that it maybe involved in some basic process of viral life cycle, but are not present in Toursvirus which includes two species (Diadromus pulchellus toursvirus 1, DpTV-1a and Dasineura jujubifolia toursvirus 2, DjTV-2a). Thus far it is uncertain whether 3H-21 and its homologs are functional genes. $3 h-21$ is one of conserved gene which homologues encoding structural protein in TnAV-6a (ORF 4), SfAV-1a (ORF 17) and HvAV-3i (ORF 22) ${ }^{[17-19]}$. In this study, we analyzed the $3 h-21$ gene by examining transcription of the gene and expression of its protein product in HvAV-3h infected Helicoverpa armigera larvae, finding that the $3 h-21$ is indeed expressed and that the $3 \mathrm{H}-21$ protein is located on the virion of HvAV-3h.

\section{Materials and Method}

1. Insects and viruses

HvAV-3h was isolated by Huang et al. and stored in Huang's laboratory. HvAV-3h was propagated in $H$. armigera larvae as described previously[20]. A laboratory colony of $H$. armigera insects 
was cultured on an artificial diet at $27 \pm 1{ }^{\circ} \mathrm{C}$ and a 16/8 h (light/dark) photoperiod according to Yu et al. ${ }^{[21]}$.

\section{Computational analysis}

The sequence was analyzed using the Scratch protein predictor (http://scratch. proteomics.ics.uci.edu/) and NLS Mapper (http://nls-mapper.iab.keio.ac.jp/cgi-bin/NL S_Mapper_form.cgi) for prediction of gene homologues, conserved domains, motifs, signal peptide and nuclear localization signals $^{[22]}$. Protein comparisons with entries in the updated GenBank/EMBL, SWISS-PROT and PIR databases were performed with BLAST (https://blast.ncbi.nlm.nih. gov/Blast.cgi). Multiple sequence alignment was performed with CLUSTALX (version 1.83) and Gene Doc.

\section{Generation of anti-3H-21 antiserum}

The $3 h-21$ was amplified from the HvAV-3h genomic DNA by PCR using an upstream primer 3h-21-F (5'-GGATCCAT GTCAATATCCAGTGTATCCG-3', with a BamH I site underlined) and a downstream primer 3h-21-R (5'-CTCGAGTCAGTCG GTTGGTAATCTACAC-3', with a Xho I site underlined). The PCR product was inserted into pGEM-T Easy vector (Promega, USA), then digested with BamH I and Xho I, and was ligated into the expression vector pET-28a(+) (Novegen, GER).

The $3 \mathrm{H}-21$ fusion protein with a $6 \times$ His tag was expressed in E. coli BL21(DE3) by inducing with $1 \mathrm{mM}$ isopropyl $\beta$-D-1thiogalactopyranoside (IPTG) at $37^{\circ} \mathrm{C}$ for
$12 \mathrm{~h}$, and the $6 \times$ His-tagged recombinant $3 \mathrm{H}-21$ protein was purified on proteinlso Ni-NTA resin code column (TransGen Biotech, CHN). The purified protein was injected subcutaneously to immunize New Zealand white rabbits ${ }^{[23]}$. The prepared polyclonal rabbit antiserum against $3 \mathrm{H}-21$ was used for the immunoassays.

\section{Virion purification}

Newly molted $(6-12 \mathrm{~h})$ third-instar $H$. armigera larvae were inoculated with HvAV-3h as described previously ${ }^{[24]}$. The hemolymphs of morbid larvae were collect 7 days post infection and suspended in ice-cold TE buffer (10 Mm Tris, $1.0 \mathrm{mM}$ EDTA, $\mathrm{pH}$ 7.4) in the presence of protease inhibitors. The suspension was solicited for $15 \mathrm{~s}$ at $10 \mathrm{~W}$, layered onto a 25 to $55 \%(\mathrm{w} / \mathrm{v})$ sucrose gradient and then centrifuged at $4{ }^{\circ} \mathrm{C}$ for $1.5 \mathrm{~h}$ at $72,100 \mathrm{~g}$. The virion bands were collected, diluted fivefold with TE buffer and centrifuged for $1 \mathrm{~h}$ at $4^{\circ} \mathrm{C}$ at $110,000 \mathrm{~g}$ to sediment the virions (Hou et al., 2013). The purity of virions in negative staining was checked by transmission electron microscopy (TEM).

\section{Western blotting}

Protein concentrations were determined by the method of Bradford. Virion proteins were fractionated by SDS-PAGE, blotted on Nitrocellulose membranes (NC) by semi-dry electrophoresis transfer. Using an anti-3H-21 antiserum as the primary antibody (diluted 1:5000) for $1 \mathrm{~h}$ at room temperature, followed by alkaline 
phosphatase conjugated anti-rabbit antibodies (1:5000). Further treatments as described previously ${ }^{[14]}$. Lysates of mock-infected third-instar $H$. armigera larvae were used as a negative control, and infected with HvAV-3h served as a positive control.

\section{Tanstription analysis}

To confirm expression and analyze temporal expression of $3 h-21$ in $H$. armigera larvae, total RNA was isolated from mock-infected and third-instar $H$. armigera larvae infected with HvAV-3h for different time points $(0,3,6,12,24,48,72,96,120$ and $168 \mathrm{hpi}$ ) using the Trizol RNA extraction kit (TaKaRa, JPN) according to the manufacturer's protocol.

The cDNA was synthesized with the total RNA by using a PrimeScript II 1st Strand cDNA Synthesis kit (TaKaRa) following the protocol specified by the manufacturer. The primers used were the 3h-21-specific primers (as above), the mcp-specific primers mcp-F (5'-GGATCCATGACTTCAAACA CAGAAACGC-3', BamH I site underlined) and mcp-R(5' -CTCGAGTTAATTGAAA TCGCCTCCG-3', Xho I site underlined), and the gapdh-specific primers gapdh-F (5) -ATGTCCAAAATCGGTATCAACG-3') and gapdh-R (5'-TTAATCCTTGGTCTG GATGTACT-3'). The subsequent PCR was performed with 35 cycles and then the PCR products were analyzed on a $1.0 \%$ agarose gel.

\section{Expression analysis}

Early third-instar $H$. armigera larvae were inoculated with HvAV-3h as described previously. Mock-infected larvae were taken as a control and the GAPDH as a positive control. The morbid larvae were collected at various time points $(0,3,6,12,24,48,72,96,120$ and 168 hpi) post infection and extracted by RIPA (Solarbio, CHN) according to manufacturer's suggested protocol. Protein samples were separated by SDS-PAGE after lysed in SDS-PAGE loading buffer by boiling for 10min and the procedures of western blot analysis as described above.

8. Fluorescence microscopy analysis The third-instar $H$. armigera larvae inoculated with HvAV-3h were collected at different time points (48, 96, and 120 hpi). The abdominal segments of the larval body were cut and fixed with $4 \%$ paraformaldehyde. The samples were then dehydrated and embedded in paraffin. The paraffin sections immersed in the distilled water after removed paraffin. Paraffin-embedded tissue sections designated for immunohistochemical staining require several pretreatment steps, including the removal of paraffin from and the rehydration of tissue sections and the retrieval of antigenicity. The next steps were carried out according to standard methods ${ }^{[25]}$. The stained sections were observed under the microscope and were photographed. The mock-infected larvae served as control. 


\section{Results}

1. Sequence analysis of $3 \mathrm{H}-21$ and its homologues

The $3 h-21$ gene is 687 nucleotides in length, theoretically encoding a protein with molecular weight of $25.6 \mathrm{kDa}$ and pI of 5.86 . BLAST search of GenBank indicated that the predicted protein was present in all ascovirus except the members of Toursvirus and most homologous to HvAVs and SfAV-1a proteins respectively. (See figure $1)$.
2. Transcription analysis of $3 \mathrm{~h}-21$

To see whether $3 h-21$ was transcribed, RT-PCR analysis was performed with total RNA purified from mock-infected and HvAV-3h-infected H.armigera larvae at various times. This analysis served to provide information about temporal regulation and the sizes of $3 h-21$ transcripts. A single band of the expected size (approximate $0.7 \mathrm{~kb}$ ) was detected as early as 6 hpi, which remained stably detectable to $168 \mathrm{hpi}$. The transcript size

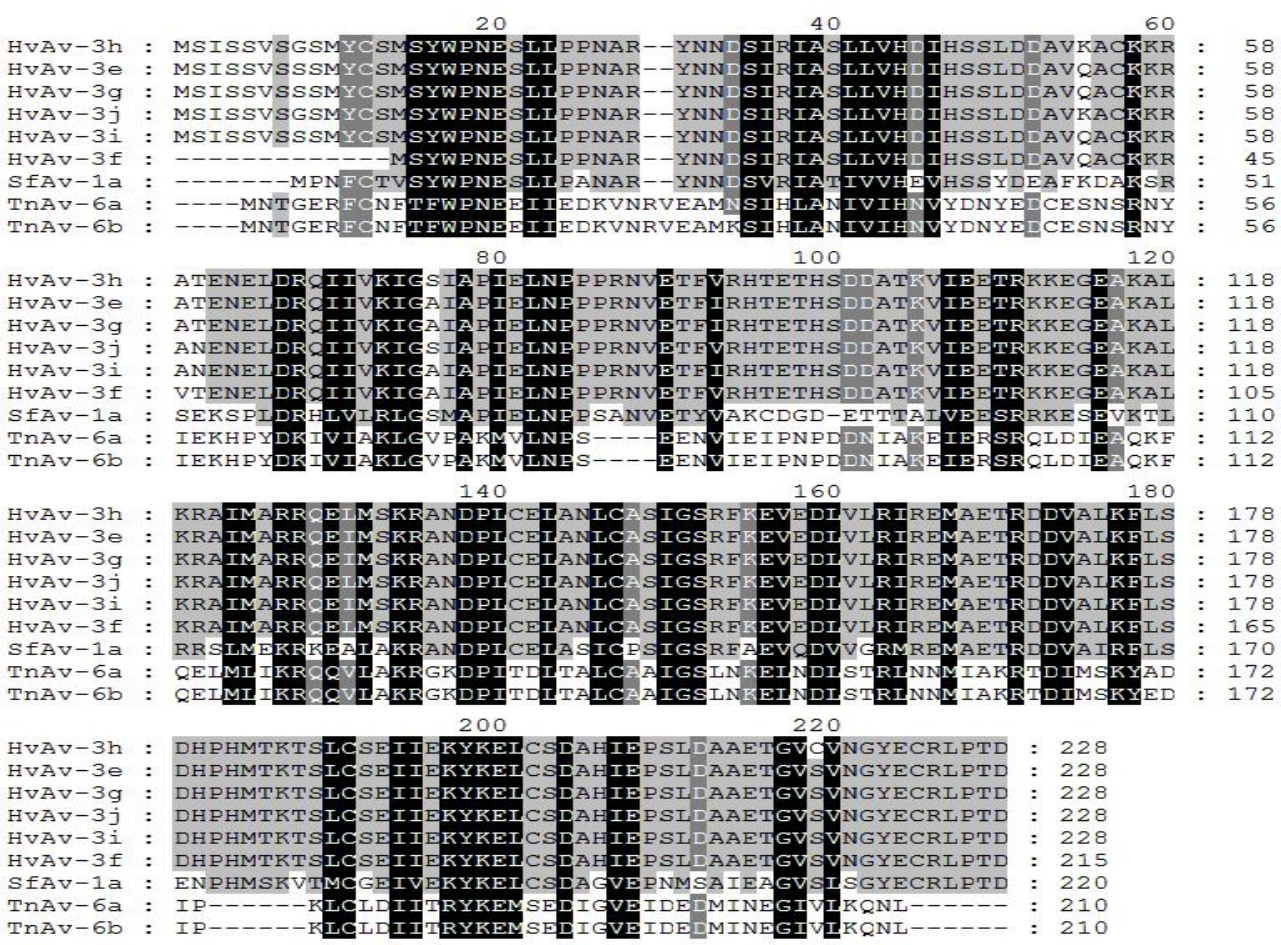

Figure 1. Multiple sequence alignment of 3H-21 and its homologues.

Black shading: 100\% identity. Dark grey shading: 85\% identity. Light grey shading: 70\% identity.

Alignment of 3H-21 homologs encoded by Spodoptera frugiperda ascovirus 1a (SfAV-1a), and various isolates of Heliothis virescens ascovirus (HvAV-3e, $-3 f,-3 g,-3 i,-3 j)$. Abbreviations and data sources with GenBank accession numbers in parentheses: HvAV-3h, ORF 21 (AYD68152.1); HvAV-3j, ORF 23 (BBB16493.1); HvAV-3e, ORF 23 (YP 001110876.1); HvAV-3g, ORF 24 (YP 009701680.1); HvAV-3i, ORF 22 (AXN-77205.1); HvAV-3f, ORF 22 (YP_009701488.1); SfAV-1a ORF 17 (YP_762372.1). 
in tune with predicted size of $687 \mathrm{bp}$. In contrast, the mcp fragment (1368 bp) was detectable at 3-96 hpi. No signal was amplified from the RNA isolated from mock-infected larvae.

3. Immunodetection of the $3 \mathrm{H}-21$ protein in vivo and in virus particles

Protein extracts of mock-infected and third-instar H.armigera larvae infected with $\mathrm{HvAV}-3 \mathrm{~h}$ isolated at different time points $(0,3,6,12,24,48,72,96,120$ and $168 \mathrm{hpi}$ ) were separated by SDS-PAGE and subjected to western blot analysis using the 3H-21-specific rabbit antiserum. This polypeptide was first detected at 48 hpi and remained detectable up to $168 \mathrm{hpi}$ (See figure 2). No specific immuno-reactive band was detected from mock-infected control larvae. The protein size of $25.6 \mathrm{kDa}$ was in agreement with the predicted molecular weight, suggesting that no major post translational modification of the $3 \mathrm{H}-21$ protein occurred.

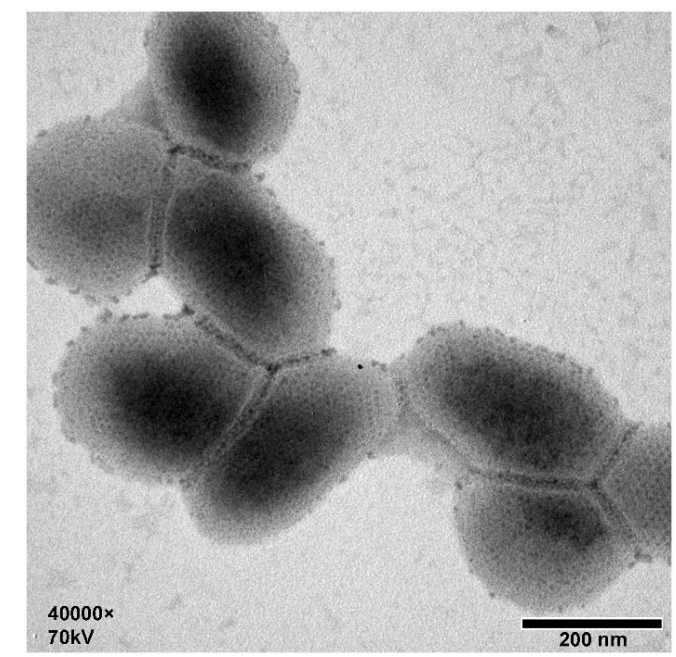

Figure 2. Purification of HvAV-3h virions were examined by TEM analysis.

To investigate whether the $3 \mathrm{H}-21$ protein is a structural protein, western blot analysis was carried out on purified HvAV-3h virions (See figure 3 and 4). Protein extracts of HvAV-3h-infected larvae isolated at 120 hpi were separated by SDS-PAGE and subjected to western blot analysis using the 3H-21-specific rabbit antiserum (See figure 5). The antibody did not react to mock-infected larvae but reacted strongly with a 25.6 $\mathrm{kDa}$ protein at virions and $120 \mathrm{hpi}$, suggesting that the $3 \mathrm{H}-21$ protein is a constituent of HvAV-3h virions. MCP was a widely identified structural protein among ascoviruses, in tune with the $3 \mathrm{H}-21$. As a reference protein in host, GAPDH react to extract of mock-infected and infected larvae but did not reacted with virions. 

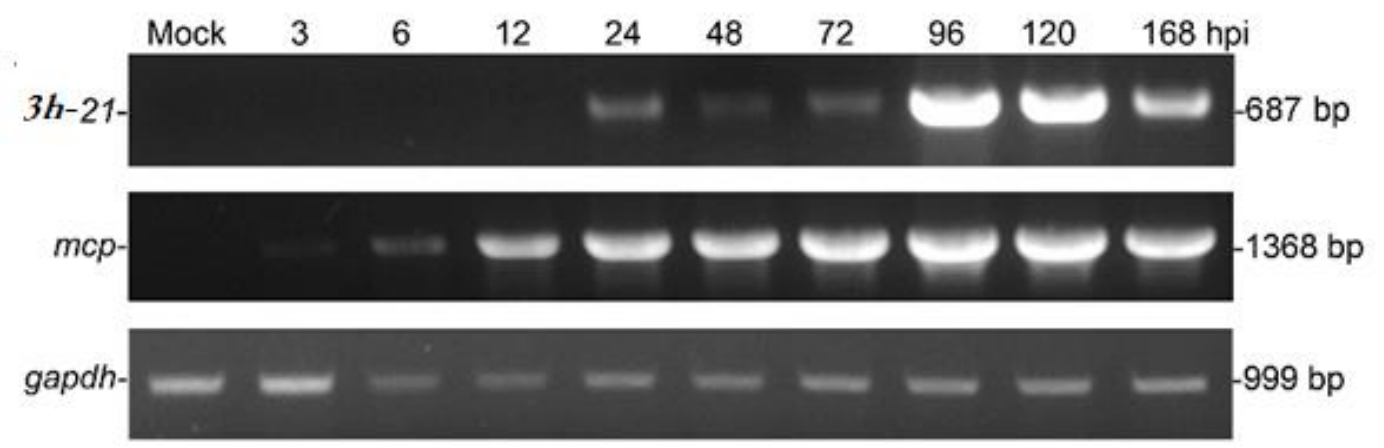

Figure 3. Transcription analysis of $3 h-21$ in HvAV-3h infected H. armigera larvae.

Total RNA was extracted from HvAV-3h infected H. armigera larvae at 3, 6, 12, 24, 48, 72, 96, 120 and 168 hpi or mock-infected larvae. PCR was performed, and the amplification products were subsequently analyzed electrophoresis in a $1.0 \%$ agarose gel. Mcp is a positive control for structural protein genes, and gapdh is a internal loading control.

$\begin{array}{rllllllllll}\text { Mock } & \text { M } & 3 & 6 & 12 & 24 & 48 & 72 & 96 & 120 & 168 \text { hpi } \\ 3 \mathrm{H}-21- & & & & & & & & & & \end{array}$

\section{GAPDH-}

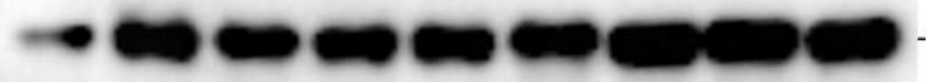

$-36.5 \mathrm{kDa}$
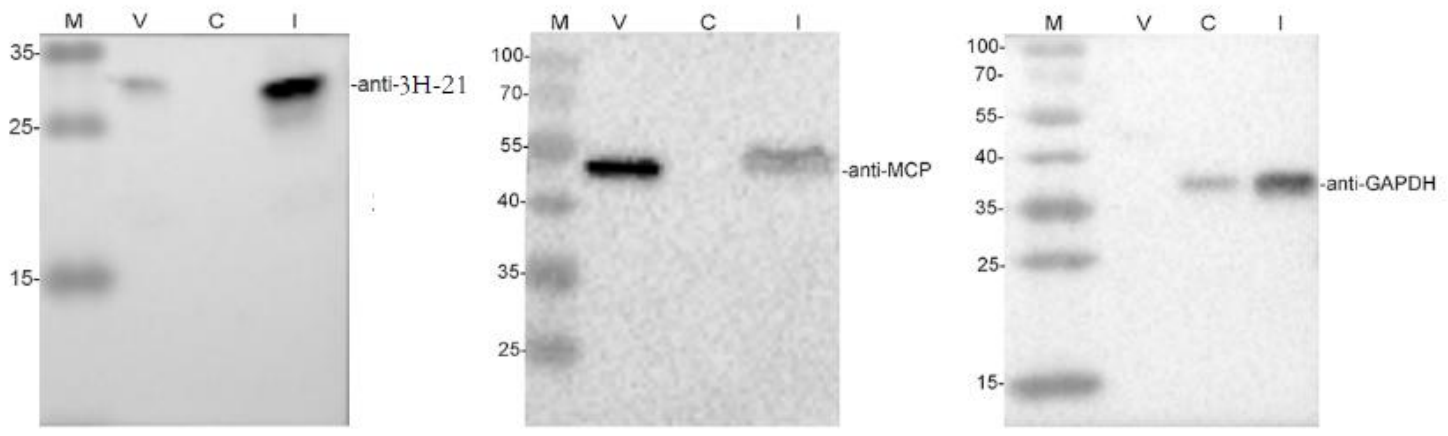

Figure 4. Western blot analysis of 3H-21.

(a) Western blot analysis of 3H-21 in HvAV-3h-infected H. armigera larvae from 3 to 168 hpi lane numbers correspond to time p.i..Mock-infected larvae and GAPDH used as controls. (b) Western blot analysis of 3H-21 in the purified HvAV-3h virions. Virions (V lane 2) (2 mg per lane each), mock-infected third-instar H. armigera larvae (C lane 3), Lysates of HvAV-3h-infected third-instar H. armigera larvae (120 h p.i.) (I lane 4) were analysed by SDS-PAGE and western blot analysis. Size standards are indicated on the left; the single $25.6 \mathrm{kDa}$ immunoreactive protein is indicated on the right. 


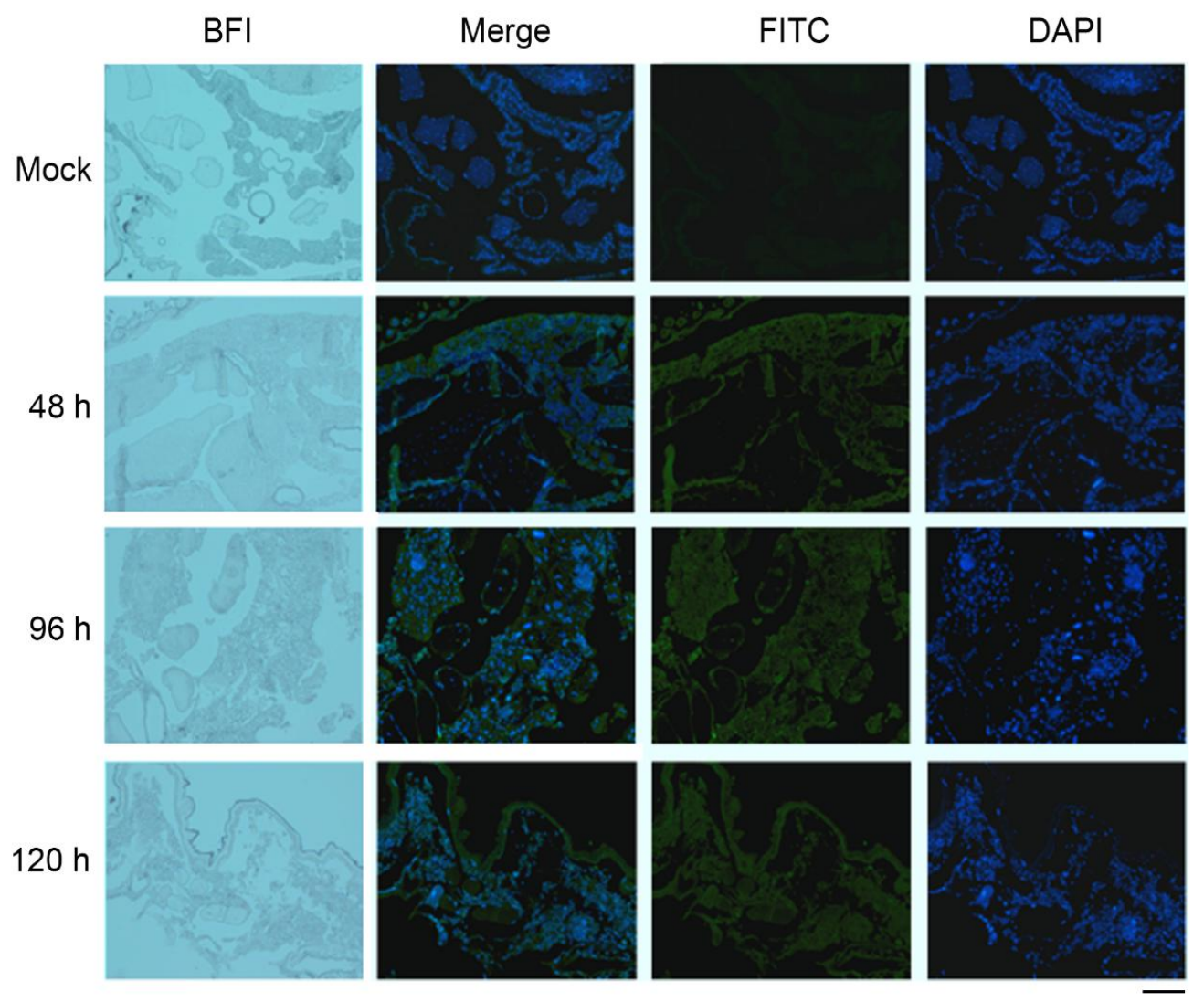

Figure 5. Immunohistochemistry analysis.

The fat body tissues from third-instar $H$. armigera larvae infected by HvAV-3h at different points post infection (shown at the left). Fluorescence microscopy shows the progression of $3 \mathrm{H}-21$ proteins in larvae from 48 to $120 \mathrm{hpi}$. Scale bar $100 \mathrm{~nm}$.

\section{Localization of $3 \mathrm{H}-21$ proteins in insect}

Immunohistochemical staining was carried out with against $3 \mathrm{H}-21$ rabbit antiserum as the primary antibody after paraffin-embedded tissue sections removing paraffin from and retrieving antigenicity. The immunohistochemistry results showed that no strong green fluorescence signal was detected in all tissues of mock-infected larvae, indicating that no expression of
$3 \mathrm{H}-21$ protein. The positive signal was observed in most fat body cells $48 \mathrm{hpi}$, indicating the expression of $3 \mathrm{H}-21$ protein. At $92 \mathrm{hpi}$, the nucleus of fat body became swollen and the positive signal distributed both inside and outside the nucleus; 120 hpi, the constitution of fat body were completely destroyed, most of the cells showed positive signal, and $3 \mathrm{H}-21$ protein was largely expressed. 


\section{Disccusions}

In this study, we have described the identification a novel structural protein of HvAV-3h. This protein, encoded by $3 \mathrm{H}-21$, is hitherto unique to Ascovirus and has not been found in any other Toursvirus to date. The coding region of $3 \mathrm{H}-21$ potentially encodes a $25.6 \mathrm{kDa}$ protein, which is close to the actual size of the protein confirmed by western blot analysis with the prepared $3 \mathrm{H}-21$ antiserum. This suggests that the protein is not extensively modified post-translation, for example, by glycosy-lation. This is agree with other characteristics of $3 \mathrm{H}-21$, as it does not have a signal sequence or a Golgi retention signal were predicted with Scratch protein predictor.

$3 h-21$ is a conserved gene with homologues in all Ascovirus, specifically various isolates of $\mathrm{HvAV}(-3 \mathrm{j},-3 \mathrm{e},-3 \mathrm{~g},-3 \mathrm{i}$, $-3 \mathrm{f})$ and SfAV-1a. The ORF 22 from HvAV-3i identified as a structural protein share $97 \%$ homology with $3 \mathrm{H}-21^{[17]}$, the ORF 17 from SfAV-1a (now the type species of Ascoviridae) share 61\% homology ${ }^{[18]}$, and the ORF 4 from TnAV-6a share $30 \%$ homology ${ }^{[19]}$.

To elucidate the function of $3 \mathrm{H}-21$, we analyzed the transcription and expression of $3 \mathrm{H}-21$ in HvAV-3h-infected $H$. armigera larvae. RT-PCR showed that $3 h-21$ transcription started at $6 \mathrm{hpi}$, but western blot analysis suggested that $3 \mathrm{H}-21$ was first detected at $48 \mathrm{~h}$ and continued to be present at $168 \mathrm{hpi}$. This type of temporal expression also exit in our other study of structural protein in HvAV-3h ${ }^{[16]}$. Ascoviruses have unique structural and biological characteristic which distinguish from other insect virus. Considering this, this type of temporal different from transcription and expression may cause by the unique feature of ascovirus. The functions and precise location of $3 \mathrm{H}-2 \mathrm{I}$ in the virion have not been elucidated fully. This may suggest that the $3 \mathrm{H}-21$ protein either plays a role in the assembly of ascovirus virion.

So far, three structural proteins, MCP, P64 and 3H-117 have been investigated to be essential factors for ascoviruses which is highly conserved among Ascoviridae, Iridoviridae [15,16,18,19]. MCP has been described previously in TnAV-2a as one of major structural proteins. And used for the evolutional study of several related dsDNA viruses ${ }^{[15]}$. P64 is another most abundant protein in SfAV-1a as a structural protein required for packaging of the large viral genome into the virion during assembly ${ }^{[14]}$. An intriguing finding suggests that P64 interacting with other structural proteins as a unit could condense and release gDNA in the virions [26]. $3 \mathrm{H}-117$ is conserved among all sequenced ascoviruses which have identified as a structural protein in HvAV-3h with a typical sub-cellular transport from nucleus to cytoplasm [16].

As reported previously, HvAV-3h infection leads to destructive pathological 
changes in the host larval fat bodies. Hematoxylin-eosin staining of larval transverse sections from HvAV-3h infected $H$. armigera larvae, illustrating the pathological morphology among different tissues. The fat bodies of the HvAV-3h infected larvae had disintegrated into debris in $72 \mathrm{hpi}$ but no distinct differences were found in the muscle and gut tissues during the same time period [27]. In this report, immunohistochemical analysis were carried out to suggest the expression of structural proteins or virions in larvae tissues represented by $3 \mathrm{H}-21$, which reveals the pathogenic process of HvAV-3h in the fat bodies of infected $H$. armigera larvae. Our results are consistent with the H.E staining analysis by Li et al.

In conclusion, $3 h-21$ was identified as a conserved gene in Ascovirus encoding a component protein of $\mathrm{HvAV}-3 \mathrm{~h}$ virion. Further experiments would allow the determination of possible interactions of these structural proteins and how these proteins enable $\mathrm{HvAV}-3 \mathrm{~h}$ to set up a successful infection in vivo, and to elucidate the structure and organization of ascoviral virions. This study establish a foundation for further investigation of ascoviral virions.

\section{Statement of Author Contributions}

Y.Z., H.Y., N.L., G.H.H. conceived and designed the experiments. Y.Z. performed the experiments and wrote the manuscript. All the authors discussed and commented on the manuscript.

\section{Acknowledgments}

The authors would like to thank Mrs. Youlin Zhu (Wuhan Institute of Virology, Wuhan, China) for her help during antibody preparation. This study was supported partly by the National Natural Science Foundation of China (31872027).

\section{References}

[1]. Liu YY, Xian WF, Xue J, et al. Complete genome sequence of a renamed isolate, Trichoplusia ni ascovirus 6b, from the United States[J]. Genome Announcements, 2018, 6(10): UNSP e00148-18.

[2]. Huang GH, Hou DH, Wang $\mathrm{M}$, et al. Genome analysis of Heliothis virescens ascovirus $3 \mathrm{~h}$ isolated from China[J]. Virologica Sinica, 2017, 32 (2):147-154.

[3]. Arai E, Ishii K, Ishii H, et al. An ascovirus isolated from Spodoptera litura (Noctuidae: Lepidoptera) transmitted by the generalist endoparasitoid Meteorus pulchricornis (Braconidae: Hymenoptera)[J]. Journal of General Virology, 2018,99 (4):574-584.

[4]. Li SJ, Wang X, Zhou ZS,et al. A comparison of growth and development of three major agricultural insect pests infected with Heliothis virescens ascovirus $3 \mathrm{~h}$ (HvAV-3h) [J]. PLoS ONE, 2013, 8(12): e85704.

[5]. Asgari S, Bideshi DK, Bigot Y, et al. ICTV Virus Taxonomy Profile: Ascoviridae[J]. Journal of General Virology, 2017, 98 (1): 4-5. 
[6]. Bideshi DK, Demattei MV, Rouleux-Bonnin F, et al. Genomic sequence of Spodoptera frugiperda ascovirus 1a, an enveloped, double-stranded DNA insect virus that manipulates apoptosis for viral reproduction[J]. Journal of Virology, 2006, 80 (23): 11791-11805.

[7]. Bigot Y, Rabouille A, Sizaret PY, et al. Particle and genomic characteristics of a new member of the Ascoviridae: Diadromus pulchellus ascovirus $[\mathrm{J}]$. Journal of General Virology, 1997, 78 (5): 1139-1147.

[8]. Wang L, Xue J, Seaborn CP, et al. Sequence and organization of the Trichoplusia ni ascovirus 2c (Ascoviridae) genome $[\mathrm{J}]$. Virology, 2006, 354 (1): 167-177.

[9]. Asgari S, Davis J, Wood D, et al. Sequence and organization of the Heliothis virescens ascovirus genome $[\mathrm{J}]$. Journal of General Virology, 2007, 88: 1120-1132.

[10]. Wang J, Yang M, Xiao H, et al. Genome Analysis of Dasineura jujubifolia Toursvirus 2, A Novel Ascovirus[J]. Virologica Sinica, 2019: $1-9$.

[11]. Smede M, Furlong MJ, Asgari S. Effects of Heliothis virescens ascovirus (Hvav-3e) on a novel host, Crocidolomia pavonana (Lepidoptera: Crambidae)[J]. Journal of Invertebrate Pathology, 2008, 99 (3): 281-285.

[12]. Huang GH, Wang YS, Wang X, et al. Genomic sequence of Heliothis virescens ascovirus $3 \mathrm{~g}$ isolated from Spodoptera exigua[J]. Journal of Virology, 2012, 86 (22): 12467-12468.
[13]. Chen ZS, Cheng XW, Wang X, et al. Genomic analysis of a novel isolate Heliothis virescens ascovirus $3 \mathrm{i}$ (Hvav-3i) and identification of ascoviral repeat orfs (aros)[J]. Archives of Virology, 2018, 163 (10): 2849-2853.

[14]. Tan Y, Spears T, Bideshi DK, et al. P64, a novel major virion DNA-binding protein potentially involved in condensing the Spodoptera frugiperda ascovirus 1a genome[J]. Journal of Virology, 2009, 83 (6): 2708-2714.

[15]. Zhao K, Cui L. Molecular characterization of the major virion protein gene from the Trichoplusia ni ascovirus[J]. Virus Genes, 2003, 27 (1): 93-102.

[16]. Zhao $\mathrm{Y}, \mathrm{Yu} \mathrm{H}, \mathrm{He} \mathrm{L}$, et al. $3 \mathrm{H}-117$, a structural protein of Heliothis virescens ascovirus 3h (HvAV-3h) [J]. Virus Genes, 2019, 55 (5): 688-695.

[17]. Chen ZS, Cheng XW, Wang X, et al. Proteomic analysis of the Heliothis virescens ascovirus 3i (HvAV-3i) virion [J]. Journal of General Virology, 2018, 100 (2): 301-307.

[18]. Tan Y, Bideshi DK, Johnson JJ, et al. Proteomic analysis of the Spodoptera frugiperda ascovirus 1a virion reveals 21 proteins [J]. Journal of General Virology, 2009, 90: 359-365.

[19]. Cui L, Cheng X, Li L, et al. Identification of Trichoplusia ni ascovirus $2 \mathrm{c}$ virion structural proteins. Journal of General Virology, 2007, 88: 2194-2197 
[20]. Huang GH, Garretson TA, Cheng XH, et al. Phylogenetic position and replication kinetics of Heliothis virescens ascovirus $3 \mathrm{~h}$ (Hvav-3h) isolated from Spodoptera exigua [J]. PLoS ONE, 2012,7 (7): e40225.

[21]. Yu H, Li ZQ, He L, et al. Response analysis of host Spodoptera exigua larvae to infection by Heliothis virescens ascovirus $3 \mathrm{~h}$ (HvAV-3h) via transcriptome [J]. Scientific Reports, 2018, 8: 5367.

[22]. Kosugi S, Hasebe M, Tomita M, et al. Systematic identification of cell cycle-dependent yeast nucleocytoplasmic shuttling proteins by prediction of composite motifs $[\mathrm{J}]$. Proceedings of the National Academy of Sciences of the United States of America,2009, 106 (25):10171-10176.

[23]. Li XF, Yu H, Zhang CX, et al. Helicoverpa armigera nucleopolyhedrovirus orf 81 is a late gene involved in budded virus production[J]. Archives of Virology, 2014,159 (8): 20112022.
[24]. Federici B A, Vlak JM, Hamm JJ. Comparative study of virion structure, protein composition and genomic DNA of three ascovirus isolates [J]. Journal of General Virology, 1990, 71: 1661-1668.

[25]. Boenisch T. Pretreatment for immunohisto-chemical staining simplified [J]. Applied Immunohistochemistry \& Molecular Morphology, 2007, 15 (2): 208-212.

[26]. Bideshi DK, Demattei MV, Rouleux-Bonnin F, et al. Genomic sequence of Spodoptera frugiperda ascovirus 1a, an enveloped, double-stranded DNA insect virus that manipulates apoptosis for viral reproduction [J]. Journal of Virology, 2006, 80 (23): 11791-11805.

[27]. Li ZQ, Yu H, Huang GH. Changes in lipid, protein and carbohydrate metabolism in Spodoptera exigua larvae associated with infection by Heliothis virescens ascovirus $3 \mathrm{~h}[\mathrm{~J}]$. Journal of Invertebrate Pathology, 2018, 155: 55-63. 